\title{
A materialidade dos discursos sobre a pessoa com deficiência física neuromotora/paralisia cerebral
}

\author{
The materiality of discourses about neuromotor \\ physical disability/cerebral paralysis
}

Claudovil Barroso de Almeida Júnior ${ }^{1}$

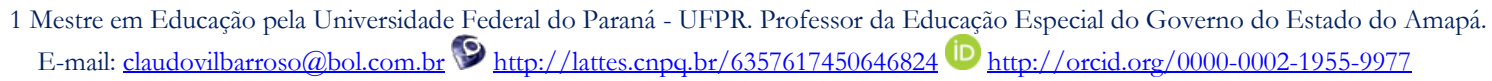

RESUMO: Historicamente, a pessoa com deficiência física neuromotora/paralisia cerebral ao nascer carrega simbolicamente conceitos que lhes são atribuídos em razão desta não corresponder às expectativas sociais. Dessa maneira, tendo o anseio de observar como os mesmos se materializam, o estudo tem como objetivo analisar as concepções presentes nos discursos sobre a pessoa com deficiência física neuromotora/paralisia cerebral em produções artísticas, como também acadêmicas. Metodologicamente, utilizou-se a pesquisa descritiva de caráter qualitativo, com a investigação de trabalhos que dialogam com a temática em evidência. Quanto aos resultados, observa-se que a materialidade dos discursos sobre a pessoa com deficiência física neuromotora/paralisia cerebral se encontra em um território que subverte esse sujeito, reforçando uma anormalidade produzida ideologicamente, com a finalidade de moldá-lo para ser aceito socialmente. Logo, é necessário que as concepções superem a visão mecanicista sobre essa pessoa, com respeito às diferenças, colaborando para o seu empoderamento como interlocutora de resistências e lutas contra sua exclusão no contexto social.

Palavras-chaves: Deficiência Física Neuromotora; Paralisia Cerebral; Discursos.

\begin{abstract}
Historically, the person with neuromotor disability/cerebral palsy at birth symbolically carries concepts attributed to them because it does not meet social expectations. Thus, having the desire to observe how they materialize, the study aims to analyze the conceptions present in the discourses about the person with neuromotor disability/cerebral palsy in artistic as well as academic productions. Methodologically, it was used the descriptive research of qualitative character, with the investigation of works that dialogue with the subject in evidence. As for the results, it is observed that the materiality of the discourses about the person with neuromotor disability/cerebral palsy is in a territory that subverts this subject, reinforcing an abnormality produced ideologically, with the purpose of shaping it to be socially accepted. Therefore, it is necessary for the conceptions to overcome the mechanistic view of this person, with respect to differences, contributing to their empowerment as an interlocutor of resistances and struggles against their exclusion in the social context. Keywords: Neuromotor Physical Disability; Cerebral Palsy; Speeches.
\end{abstract}

\section{INTRODUÇÃO}

A história de vida de pessoas com deficiência, especialmente com deficiência física neuromotora/paralisia cerebral é cheia de lutas e resistência desde o nascimento, isto porque a construção de sua identidade está atrelada a uma sociedade que fortemente a demarca por se diferir do outro, caracterizado como normal. Esta constatação pode ser observada mediante a uma rede de discursos, advindos de múltiplos contextos sociais, que constantemente é caracterizada e/ou simbolizada pelo abandono e exclusão social.

Nessa perspectiva, o estudo tem por objetivo analisar as concepções presentes nos discursos sobre a pessoa com deficiência física neuromotora/paralisia cerebral em produções artísticas, como também acadêmicas. A metodologia contemplou a pesquisa descritiva de 
caráter qualitativo que, demandou investigar trabalhos que dialogam com a temática sobre os sujeitos que se encontram na condição de pessoa que possui a deficiência em destaque.

Assim sendo, a reflexão inicial parte sobre a concepção atribuída à pessoa com deficiência física neuromotora/paralisia cerebral na atualidade, perpassando por produções que possam fundamentar a discussão sobre aspectos no que diz respeito à alteridade desse sujeito, que precisa ser concebido por meio do olhar socioantropológico mediante a ruptura de um corpo estigmatizante, para empoderarse em busca de uma sociedade com perspectivas inclusivas.

\section{A MATERIALIDADE DOS DIS- CURSOS SOBRE A PESSOA COM DEFICIÊNCIA FÍSICA NEURO- MOTORA/PARALISIA CEREBRAL}

No século XXI, a definição de pessoa com deficiência encontra-se em constante reinterpretação na ciência, como também por meio das políticas públicas que preveem a acessibilidade e/ou a inclusão, diante de discursos legais e teóricos que subsidiam a área. No entanto, o que se presencia é que, ao nascer, a criança com deficiência física neuromotora/paralisia cerebral, carregará estigmas sociais, simbolizados em apelidos, impedindo-a, "muitas vezes, de vivenciar não só seus direitos de cidadão, mas de vivenciar plenamente sua própria infância" (AMARAL, 1998, p. 12).

Essa concepção preconceituosa arraigada à sociedade, diz respeito ao modelo de educação destinada à população, que independente de sua classe social foi estimulada a não tolerar o outro que se difere em relação às características biológicas sempre tidas como universais, repercutindo em sucessivas discriminações, tendo como consequência a marginalização social, fazendo com que haja uma inviabilidade deste ser exercer com empoderamento sua cidadania.
Assim, considera-se que as diferenças físicas apresentam a capacidade de estabelecer sucessivos parâmetros advindos da sociedade, objetivando comprovar "o desvio, a anomalia, a anormalidade, e, em consequência, o ser/estar diferente ou desviante, ou anômalo, ou anormal" (AMARAL, 1998, p.13). Em razão dos padrões sociais reafirmarem insistentemente a perfeição mediante um corpo branco, elitista, heterossexual, cristão, mentalmente sadio, belo e produtivo. Desta forma, o que se percebe é a aproximação, ao que é perfeito no intuito de perseguir socialmente para categorizar o outro como normal.

Além disso, observa-se que o universo se encontra rodeado de paradigmas construídos coletivamente que, demarcam do outro e pelo outro, mediante as inúmeras narrativas sociais sobre: pretos, homossexuais, ateus, frequentadores das religiões de matriz africana, surdos, gordos..., induzindo na opinião do senso comum, mediante uma distorção perceptiva acumulada, incorporando como natural.

Essa distorção naturalizada constantemente é difundida pela mídia que repassa informações deturpadas que não apresentam nenhuma qualidade científica, diante do discurso do politicamente correto, com a banalização das diferenças.

De acordo com Amaral (1998), a sociedade ao reconhecer a diferença do outro entra em constante desconforto, em razão de que ela gera um profundo mal-estar, tensão e ansiedade, porque não estamos preparados para conviver com aquele que foge das normas estabelecidas pelo padrão social. Esse contexto fica bastante nítido quando esse outro apresenta a deficiência física neuromoto$\mathrm{ra} /$ paralisia cerebral e pretende acessar o mundo do trabalho, pelo fato de não corresponder às expectativas sociais.

$\mathrm{O}$ acesso ao mundo do trabalho de pessoas com deficiência física neuromotora/paralisia cerebral pode gerar inúmeros questionamentos, tais como: esta pessoa encontra-se qualifi- 
cada e tem capacidade de ocupar essa vaga? Ela possuirá autonomia para desenvolver o trabalho compatível à vaga pleiteada? Ou então, gera o seguinte discurso: vou contratá-la porque é uma exigência do Ministério do Trabalho. Ao evidenciar essas falas advindas do senso comum, se expõe abaixo duas produções (charges) do cartunista Ricardo Ferraz, ressaltase nestas os estereótipos atribuídos às pessoas com deficiência, conforme os discursos entre os personagens. Também, é interessante salientar que independentemente das charges conotarem ironia, elas podem vir a retratar situações de exclusão social.

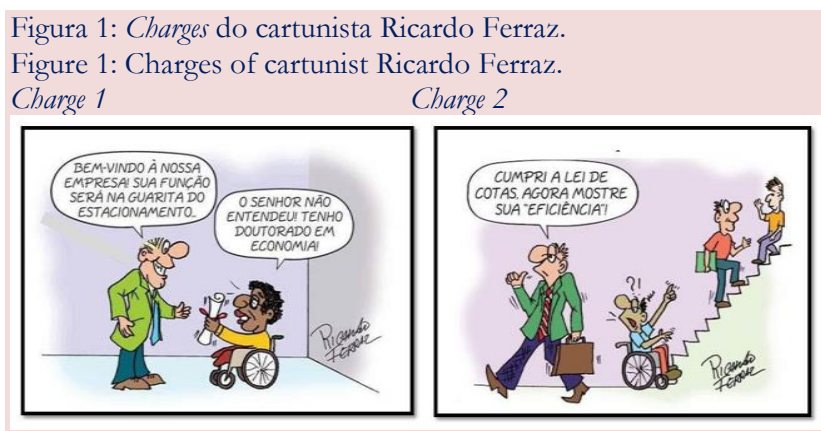

Fonte: http:// cadeiranteslife.blogspot.com.br

Ao analisar as duas charges, se observa o pré-julgamento sobre a pessoa com deficiência no mundo de trabalho. Ou seja, o que se percebe é uma atitude discriminatória, representada através do preconceito social de conceber a pessoa com deficiência física neuromotora/paralisia cerebral apenas por sua aparência física, sem atentar para as potencialidades que poderá apresentar. Ou então, como Amaral (1998) afirma: ter uma visão generosa ou de caridade sobre essa pessoa, reforçando a concepção patologizante do corpo imperfeito ${ }^{1}$, infantilizando-a em razão de um sentimento benevolente.

A oportunidade ao mundo do trabalho destinado às pessoas com deficiência não pode ser considerado como algo relacionado à be-

\footnotetext{
${ }^{1}$ Concepção patologizante do corpo imperfeito - o corpo da pessoa com deficiência é visto como aquele que tem defeito que não se ajusta ao social (sem deficiência).
}

neficência, em razão de que toda e qualquer pessoa precisa ser preparada para o mesmo, segundo a Constituição Federal (BRASIL, 1988). No entanto, o que se observa é que grande parte da sociedade considera as pessoas com deficiência física neuromoto$\mathrm{ra} /$ paralisia cerebral inapta ao trabalho. Pois, constata-se que o preconceito e a discriminação ainda estão fortemente presentes nos setores da economia, em razão da política neoliberalista que retira o direito à convivência de maneira igualitária, sobretudo, humanística com aquele que é diferente.

Apesar do direito pela inclusão da pessoa com deficiência no mundo do trabalho ser incorporado no Brasil desde a década de 1990, com a Lei 8.213/91, o que se constata é a sua parcial aplicabilidade, pois a empresa precisa se dispor para tornar o ambiente trabalhista acessível à pessoa com deficiência física neuromotora/paralisia cerebral, por meio de adaptações arquitetônicas, comunicacionais, principalmente, atitudinais, o que acarreta tempo, desencadeando em investimentos desnecessários aos empregadores, fazendo com que haja a contratação apenas por exigência do Ministério do Trabalho, em razão da isenção ou dedução fiscal.

Outro contexto que pode ser ilustrado são os estereótipos sociais encontrados na produção cinematográfica "Gaby: uma história verdadeira (1987)". A mesma retrata a trajetória de vida de Gabriela Brimmer, chamada por todos de Gaby. A personagem central era filha de pais europeus que se refugiaram no México. Ainda pequena, foi diagnosticada com deficiência física neuromotora/paralisia cerebral, fazendo com que seus pais realizassem uma peregrinação a vários médicos na esperança de um possível erro no diagnóstico, almejando a possibilidade de cura, mas todas as tentativas foram frustradas. 
Figura 2: Imagem da capa do VHS do filme "Gaby: uma história verdadeira" (1987).

Figure 2: VHS cover image from "Gaby: a true story" (1987).

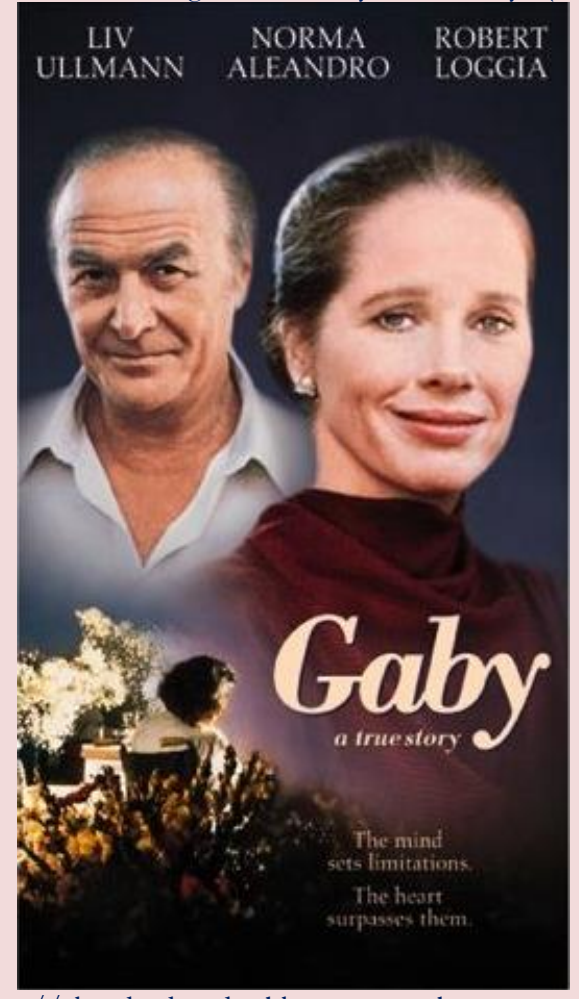

Fonte: http://almadeeducador.blogspot.com.br

Cansados, os pais de Gaby decidiram aceitá-la como era, reconhecendo que tinham um problema, optando prosseguir a vida dentro de uma possível expectativa de normalidade. Constata-se que, o ambiente familiar torna-se desestruturado com a chegada da criança diagnosticada com deficiência física neuromoto$\mathrm{ra} /$ paralisia cerebral, iniciando a fase do luto familiar e, até mesmo, da pressão social, na constituição de um núcleo familiar representativo socialmente: pai, mãe e filhos saudáveis e sem deficiência.

Assim, na intensa e complexa dinâmica familiar, a alegria é instalada quando o casal recebe a notícia da vinda de um filho, a emoção é inevitável, envolvendo todos os familiares. Os sonhos começam a povoar o imaginário humano. Mas, o filho ideal, não é o filho real, e agora? A família começa a se desestruturar, e por mais harmônica que ela seja, o sentimento de perda permanece latente, assim como emoções e sentimentos contraditórios.
[...] quando ocorre a constatação (no nascimento ou posteriormente) que um dos filhos tem características distintas do padrão culturalmente reconhecido como 'normal', a estrutura de funcionamento dessa família, inevitavelmente, se rompe. Este indivíduo pode ter uma deficiência física, intelectual, sensorial e/ou múltipla; um transtorno global de desenvolvimento, distúrbio psicológico e/ou de comportamento, altas habilidades, ou mesmo uma doença crônica e/ou fatal. (GLAT, 2012, p. 316).

Glat (2012) considera que esse sentimento dos pais em relação ao filho com deficiência é compreensível, pelo fato da idealização de um padrão cultural que é reconhecido como normal, rompendo com as expectativas do casal. Com o impacto da notícia a fase do luto se inicia para os pais, com a negação do diagnóstico. Algumas famílias conseguem aceitar essa realidade situacional, buscando orientações e informações com profissionais em relação às possibilidades de desenvolvimento para seu filho. Independentemente do seu nível sociocultural fortalece as famílias e as empodera, para estimular o desenvolvimento do filho, com perspectivas de fomentar a construção de políticas de respeito e valorização social.

A organização interna, como também os sentimentos e representações nem sempre são fáceis de serem superadas, a fase do luto é iniciada com a perda do filho que nascera com a deficiência física neuromotora/paralisia cerebral, em razão desta família não estar preparada para lidar com o outro diagnóstico.

O diagnóstico médico afirmava que provavelmente, Gaby seria "retardada?, mas possivelmente, seria inteligente, mas presa dentro de um corpo que não responde" (fala de um dos especialistas aos pais). Ela não tinha controle de seu corpo, não falava e, apenas movimentava seu pé esquerdo; todavia, seu cognitivo era preservado, porém, ela frequentou o ensino fundamental em uma escola especial. Ou seja, o diagnóstico biologicista e determinista da visão médica fez

\footnotetext{
${ }^{2}$ Termo usado na época e pelo longa metragem.
} 
com que os preconceitos sociais fossem materializados no processo educacional de Gaby.

Apesar da superproteção da família, sobretudo, da mãe, se evidencia os seguintes diálogos entre o pai e Gaby em um momento em que a mesma queria se vitimizar: "as coisas não são simples. Não pense que são difíceis só pra você. Não é verdade. Nossas limitações podem ser menos aparentes, mas são reais, como as suas. Talvez mais perigosas por serem menos visiveis!" E continuou: "nego-me ter pena de você. Nós inventamos limitações que não existem. A dificuldade é distinguir as limitações reais dos nossos próprios medos". Evidencia-se que os diálogos com o seu pai foram essenciais para a formação da personalidade da pessoa com deficiência física neuromoto$\mathrm{ra} /$ paralisia cerebral

Ao extrair os diálogos acima, observa-se a figura paterna machista, em destaque, ocupando o espaço racional, enquanto cabe à mulher ser a provedora do lar, por meio de uma visão romântica, simbolizada pelo viés emocional. Os diálogos indicam a ação sobre a vida de Gabriela Brimmer, que consegue romper as amarras do social, ao se despir simbolicamente da deficiência para conquistar sua autonomia e independência socioeducacional.

Ter coragem de emancipar-se social e politicamente é se empoderar para enfrentar as barreiras impostas. O empoderamento deve ser percebido como mecanismo de defesa das pessoas ao se posicionarem discursivamente e está presente nos múltiplos contextos sociais, denunciando as variadas violências contra as pessoas com deficiência física neuromoto$\mathrm{ra} /$ paralisia cerebral.

Além dos discursos estigmatizantes do senso comum, há também os discursos acadêmicos ou científicos que reiteram o determinismo biologicista sobre a pessoa com deficiência física neuromotora/paralisia cerebral. $\mathrm{Na}$ literatura médica, a paralisia cerebral, foi descrita inicialmente em 1843, mas a definição mais usual remete ao simpósio de Oxford, em 1959, que expressa:
Paralisia Cerebral é a sequela de uma agressão encefalopática que se caracteriza, principalmente, por um transtorno persistente - mas não invariável - do tônus ${ }^{3}$, postura e do movimento, que aparece na primeira infância e que não só é diretamente secundário a esta lesão não evolutiva do encéfalo, se não devido também à influência que tal lesão exerce na maturação neurológica”. (REBEL et al., 2010, p. 342).

Em outra referência da área médica, a pesquisadora Bobath (1971, p. 42), definiu a paralisia cerebral, como um:

[...] resultado de uma lesão ou mau desenvolvimento do cérebro, de caráter não progressivo, existindo desde a infância. A deficiência motora se expressa em padrões anormais de posturas e movimentos associados a um tônus postural anormal.

Já nos estudos de Leite e Prado (2004, p. 02), a paralisia cerebral é conceituada como:

[...] um tipo de disfunção motora presente, ou seja, o quadro clínico resultante, que inclui os tipos extrapiramidal ou discinético (atetóide, corético e distônico), atáxico, misto e espástico; e pela topografia dos prejuízos, ou seja, localização do corpo afetado, que inclui tetraplegia ou quadriplegia, monoplegia, paraplegia ou diplegia e hemiplegia.

Diante do discurso médico hegemônico, observa-se a captura do corpo imperfeito para reabilitação na perspectiva da cura. Isto é, apesar de as definições sobre a paralisia cerebral terem sido estabelecidas em momentos históricos distintos, elas são semelhantes quanto à ênfase da normalidade do indivíduo que possui essa deficiência, como um corpo doente, face ao estereótipo social que exalta o normal, o saudável e o belo.

$\mathrm{Na}$ perspectiva, de sistematizar os discursos e suas concepções sobre a deficiência físi-

\footnotetext{
3 Tônus muscular é o estado involuntário de contração dos músculos corporais, responsável por fazer com que possam entrar em ação sempre que necessário. (ISRAEL; BERTOLDI, 2010).
} 
ca neuromotora/paralisia cerebral, se realizou uma pesquisa no site do VII Congresso Brasileiro de Educação de Especial, realizado pela Universidade Federal de São Carlos, no ano de 2016, com a finalidade de analisar o foco das produções acadêmicas apresentadas nesse evento científico sobre a deficiência física. Assim, foram encontrados e analisados onze (11) trabalhos completos, de acordo com o Quadro 1 abaixo:

Quadro 1: Levantamento dos trabalhos sobre deficiência física publicados dos anais do VII Congresso Brasileiro de Educação Especial (2016)

Frame 1: List of physical disability works published from the annuals of the 7th Brazilian Congress of Special Education (2016)

\begin{tabular}{|c|c|c|}
\hline & Título & Palavras-chave \\
\hline 1 & $\begin{array}{l}\text { A (não) adoção de metodo- } \\
\text { logias diferenciadas para } \\
\text { inclusão de um aluno com } \\
\text { paralisia cerebral }\end{array}$ & $\begin{array}{l}\text { Educação Especial; Inclu- } \\
\text { são; Paralisia Cerebral. }\end{array}$ \\
\hline 2 & $\begin{array}{l}\text { A prática psicomotora como } \\
\text { contribuição para crianças } \\
\text { com deficiência física }\end{array}$ & $\begin{array}{l}\text { Psicomotricidade; Educa- } \\
\text { ção; Crianças com defici- } \\
\text { ência física. }\end{array}$ \\
\hline 3 & $\begin{array}{l}\text { Avaliação de acessibilidade } \\
\text { arquitetônica: rota percorri- } \\
\text { da por alunos com deficiên- } \\
\text { cia física na UFPA- } \\
\text { Castanhal }\end{array}$ & $\begin{array}{l}\text { Inclusão; Educação Supe- } \\
\text { rior; Acessibilidade arqui- } \\
\text { tetônica. }\end{array}$ \\
\hline 4 & $\begin{array}{l}\text { Breve descrição da deficiên- } \\
\text { cia física e seu atendimento } \\
\text { educacional }\end{array}$ & $\begin{array}{l}\text { Educação Especial; Defi- } \\
\text { ciência física; Recursos de } \\
\text { acessibilidade. }\end{array}$ \\
\hline 5 & $\begin{array}{l}\text { Deficiência motora } \\
\text { corpo cultural }\end{array}$ & $\begin{array}{l}\text { Deficiência motora; Corpo } \\
\text { orgânico; Corpo cultural. }\end{array}$ \\
\hline 6 & $\begin{array}{l}\text { Elaboração de um guia } \\
\text { ilustrado de orientações a } \\
\text { familiares de crianças com } \\
\text { deficiência neuromotora }\end{array}$ & $\begin{array}{l}\text { Relações profissional- } \\
\text { família; Fisioterapia; Guias } \\
\text { informativos }\end{array}$ \\
\hline 7 & $\begin{array}{l}\text { Estudo bibliográfico de } \\
\text { processos avaliativos de } \\
\text { crianças com paralisia cere- } \\
\text { bral }\end{array}$ & $\begin{array}{l}\text { Educação Especial; Avali- } \\
\text { ação; Paralisia cerebral. }\end{array}$ \\
\hline 8 & $\begin{array}{l}\text { Percepção de competência } \\
\text { de alunos com e sem defici- } \\
\text { ência física na execução de } \\
\text { atividades escolares: uma } \\
\text { análise comparativa }\end{array}$ & $\begin{array}{l}\text { Educação Especial; Defi- } \\
\text { ciência física; Percepção } \\
\text { de competência. }\end{array}$ \\
\hline 9 & $\begin{array}{l}\text { Perspectiva de alunos com } \\
\text { deficiência física sobre a } \\
\text { acessibilidade arquitetônica } \\
\text { na UFPA-Castanhal }\end{array}$ & $\begin{array}{l}\text { Acessibilidade; Acessibili- } \\
\text { dade arquitetônica; Defici- } \\
\text { ência física. }\end{array}$ \\
\hline 10 & $\begin{array}{l}\text { Representações } \\
\text { sobre contexto psicossocial } \\
\text { escolar do aluno com defici- } \\
\text { ência física }\end{array}$ & $\begin{array}{l}\text { Representações sociais; } \\
\text { Deficiência física; Contex- } \\
\text { to psicossocial. }\end{array}$ \\
\hline 11 & $\begin{array}{l}\text { Uso de jogos eletrônicos } \\
\text { por crianças com deficiência } \\
\text { física }\end{array}$ & $\begin{array}{l}\text { Jogos eletrônicos; Educa- } \\
\text { ção Especial; Deficiência } \\
\text { física }\end{array}$ \\
\hline
\end{tabular}

FONTE: Organização do autor (2018).
Ao analisar as pesquisas do quadro acima, percebe-se que na totalidade dos trabalhos, há uma ordem do discurso médico acentuada, que, determina fortemente a visão terapêutica e orgânica da deficiência física neuromoto$\mathrm{ra} /$ paralisia cerebral no ambiente escolar.

Dessa maneira, é importante ressaltar que é preciso que o paradigma clínico-terapêtico que concebe a educação por meio de uma metodologia reabilitadora desapareça, com perspectivas de se efetivar a concepção socioantropológica que considera e respeita a peculiaridade do indivíduo, independente de sua necessidade específica, no que tange às suas habilidades funcionais para ser incluso socioeducacionalmente (SKLIAR, 1997).

$\mathrm{Na}$ ordem dos discursos do senso-comum, da mídia, do cinema e da academia predomina uma concepção que associa a deficiência física neuromotora/paralisia cerebral a um corpo organicamente anormal, por meio de classificações estigmatizantes, ao assinalar simbolicamente suas limitações causadas pelas desordens motoras, impossibilitando que os sujeitos possam superá-las e desenvolver o cognitivo, o afetivo e o social.

Outrossim, perante as análises realizadas nos trabalhos encontrados, percebe-se que o sujeito com deficiência física neuromoto$\mathrm{ra} /$ paralisia cerebral, precisa ser estimulado precocemente para participar ativamente do processo de socio-histórico, fato este que irá refletir significativamente no processo de socialização, como também na construção de atitudes solidárias. Mas, para que essas atitudes aconteçam, é necessário que as práticas pedagógicas estejam associadas e favoreçam a uma educação de qualidade com princípios inclusivos.

Desta forma, é relevante explicitar que não se pretende negar aqui que a dimensão da compleição física constitui a identidade/subjetividade de uma pessoa com deficiência e constituiu, historicamente, a metanarrativa produzida por profissionais e especialis- 
tas fortemente medicalizada e orientada para o cuidado e o tratamento que, nas palavras de Skliar (1999, p. 19) "fracassou na compreensão e justificação de sua própria história, seus saberes, mediações e mecanismos de poder".

Nesse sentido, reafirma-se que esse estudo é uma tentativa de ruptura com a ordem do discurso dominante, colocando o sujeito como autor do seu próprio discurso, demarcando o território com sua voz, "desconstruindo a suposta ordem natural dos significados que os localizam em certos discursos e práticas de poder", rompendo com a lógica binária ${ }^{4}$ nor$\mathrm{mal} /$ anormal (SKLIAR, 1999, p. 20) que localizou a alteridade deficiente no segundo polo de oposição.

Dessa maneira, o lugar de fala dos sujeitos com deficiência, deve ser representativo ao fazer denúncias, produzir reflexões e discorrer sobre as constantes lutas e superação de sujeitos que têm a deficiência física neuromoto$\mathrm{ra} /$ paralisia cerebral podendo a vir adquirir empoderamento a partir de seus discursos, ao romper com seu corpo que fora capturado pela concepção clínico-terapêutica, reproduzidas pelo discurso normativo. Estar no centro de debates nos mais variados cenários, construindo os pilares de políticas públicas que se efetivem na garantia de direitos, compreendendo que:

a deficiência não é uma questão biológica e sim uma retórica social, histórica e cultural. A deficiência não é um problema dos deficientes ou de suas famílias ou dos especialistas. A deficiência está relacionada com a própria ideia da normalidade e com sua historicidade (SKLIAR, 1999, p 18).

Diante desse contexto, a pessoa com paralisia cerebral ${ }^{5}$ (PC) está classificada no grupo

${ }^{4}$ Lógica binária - comparação entre dois indivíduos: o normal e o anormal (SKLIAR, 1997).

${ }^{5}$ A deficiência física neuromotora/paralisia cerebral ser classificada de acordo com a qualidade do tônus: a) Espástica - presença de hipertonia com caráter permanente, mesmo em repouso. A espasticidade aumenta a das pessoas que possuem deficiência física neuromotora, cuja relação orgânico-funcional pode assumir categorias e condições muito distintas, a depender do quadro clínico diagnosticado e da efetividade dos atendimentos realizados. Importante destacar a singularidade dos quadros e sua propensão a serem mais estáveis quanto à funcionalidade física, ou situações de patologias progressivas que não poderão prescindir de atenção de saúde e cuidados específicos e constantes. Nesse aspecto é indispensável ressaltar a grande contribuição que a educação escolar deve dar a superação de limitações iniciais, já que o trabalho clínicoterapêutico dos profissionais da saúde já está amplamente consolidado em concepções e práticas.

De acordo com Silva (2014), a deficiência física compromete a motricidade do indivíduo, podendo afetar o sistema ostearticulatório, motor e nervoso. O termo paralisia cerebral caracteriza-se pela disfunção motora, irreversível e não progressiva e, acontece antes, durante ou após o nascimento.

Em suas pesquisas sobre os estudantes com paralisia cerebral, Basil (2004, p. 215) expõe que:

tentativa da criança de executar movimentos, o que faz com que estes sejam bruscos, lentos e anárquicos; b) Atetóide - apresenta tipo de tônus instável e flutuante, movimentos involuntários. Quando a pessoa tenta executar uma ação, apresenta movimentos incoordenados de pequena amplitude; c) Atáxica - presença de hipotonia com incoordenação motora. A ataxia pura é rara, Geralmente o atáxico apresenta um grau mais ou menos grave de deficiência mental. Como também, na distribuição do tônus: tetraplegia/tetraparesia - envolvimento dos quatro membros; triplegia/triparesia - envolvimento dos três membros; paraplegia/paraparesia - envolvimento dos membros inferiores; hemiplegia/hemiparesia - envolvimento de um lado do corpo (direito ou esquerdo); monoplegia/monoparesia - envolvimento de um membro do corpo. O sufixo plegia corresponde à ausência total de movimento e paresia a existência de movimentos residuais. (BRASIL, 2006). 
[...] a PC não é uma doença, mas sim um quadro ou um estado patológico ${ }^{6}$. Nesse sentido, deve-se levar em conta que a PC não pode ser curada em sentido restrito. A lesão como tal, quando existe, é irreversível; contudo, se a atenção, a reabilitação e a educação da criança forem corretas, é possível obter progressos muito importantes, que a aproximariam de um funcionamento mais normalizado. Não se deve esquecer que as faculdades de substituição e de compensação dos centros cerebrais não lesados são importantíssimas e seriam tanto mais quanto mais precoce fosse a intervenção oportuna. [...] Dessa forma, a criança com PC não deve ser considerada como uma criança doente, mas como uma pessoa com características específicas das quais decorrem necessidades que pais, amigos, professores e especialistas diversos procuram atender da melhor maneira possível.

A criança com deficiência física neuromotora, especialmente com paralisia cerebral, precisa de estímulos, independente do contexto sociocultural que está inserida, para ter autonomia e independência. Mas, para que isso ocorra, é necessário compreender que nem toda criança que apresenta esta deficiência tem deficiência intelectual, ou seja, as condições cognitivas, do raciocínio lógico, da abstração, da memória mediada, entre outras funções estão preservadas. O que ocorre é que, como a área motora da fala pode ter sido afetada, a impossibilidade de comunicação oral pode fazer parecer que há ausência desses processos.

Diante dos discursos (senso comum, midiático, literatura médica e acadêmica) analisados aqui, observou que na maior parte encontrou-se a concepção terapêutica e mecanicis$\mathrm{ta}^{7}$, o que dificulta na aquisição de um novo olhar sobre o sujeito com deficiência física neuromotora/paralisia cerebral no processo educacional. Isto porque, segundo Amaral

\footnotetext{
${ }^{6}$ Um conjunto de características relacionadas à condição do indivíduo (BASIL, 2004).

${ }^{7}$ Concepção mecanicista - concebe o corpo da pessoa com deficiência como anormal, desviante do que é estabelecido pelo social.
}

(1998), existem três critérios para definir a noção de desvio e desviante, dadas às pessoas com deficiência, sejam estes: estatísticos, estrutural/funcional e o tipo ideal.

Para Amaral (1998), o primeiro critério (estatístico) - estabelece se a pessoa com deficiência está dentro das métricas, do que é normal. O segundo critério é o estrutu$\mathrm{ral} /$ funcional - quanto o sujeito é funcional no meio em que ele vive. $O$ terceiro critério é o tipo ideal - o sujeito social é o hétero, cristão, ouvinte, branco, magro...., caso não possua essas características, é perseguido para ser moldado para se tornar normal.

Com isso, o diferente é caracterizado e representado pela pessoa com deficiência física neuromotora/paralisia cerebral que, cruza aos nossos olhares como sujeitos subversivos por não corresponder às expectativas dos modelos socialmente representados.

\section{METODOLOGIA}

A metodologia do estudo se concentrou na pesquisa descritiva, com a coleta de dados em referências bibliográficas, por meio da abordagem qualitativa. Segundo Gil (2010), a análise produzida com base na pesquisa bibliográfica objetiva reconhecer as informações contidas nos materiais coletados. Bem como, compreender as variadas formas de contribuições encontradas que podem ser utilizadas para compor outras pesquisas.

Além disso, se realizou uma leitura e análise sobre as produções encontradas, com a finalidade de investigar se elas interessavam ao estudo. A posteriori, houve a elaboração de um plano de sistematização de ideias para discorrer sobre a temática para estruturar e fundamentar o estudo.

\section{DISCUSSÕES E RESULTADOS}

Conforme as análises realizadas mediante a coleta dos materiais utilizados para fundamentar o estudo, a maioria se reporta à pessoa 
com deficiência física neuromotora/paralisia cerebral, como um sujeito neurovegetativo em razão da concepção de focar apenas o patológico e, não o social. Ao evidenciar o social, a pessoa que possui essa condição terá maiores oportunidades de ser incluída desde a infância, pois pressupõe que a comunidade já incorporou naturalmente atitudes inclusivas que favorecerão no bem-estar de todos.

Outro aspecto a considerar é que por meio dessa incorporação salutar a contratação de pessoas com deficiência física neuromotora/paralisia tornar-se-á mais receptiva, não se restringindo meramente para cumprir o que estabelece o Ministério do Trabalho, porque a contratação irá acontecer com respeito às peculiaridades que o outro apresenta, norteada pela ética, moral e, principalmente, pela imparcialidade, visto que a pessoa com deficiência precisa encontrar-se qualificada como qualquer outro profissional.

Nesse sentido, fica perceptível que o padrão socialmente estabelecido como regra, faz com que pessoas que têm essa deficiência sejam invisibilizadas constantemente e/ou não se sintam pertencentes de um grupo social, apresentando como consequência sua marginalização social e educacional. De acordo com Beyer (2006) a inclusão acontece quando pessoas com e sem deficiência convivem juntas, oportunizando a interação das diferenças, no propósito de adquirir conhecimentos enriquecedores, sob a perspectiva inclusiva para todos.

A ausência da convivência pacífica entre e com as diferença reforça a visão estigmatizante, apresentando como consequência a exclusão social da pessoa com deficiência física neuromotora/paralisia cerebral, que não se adequa aos preceitos de um grupo, em razão de discursos ideológicos que se perpetuam com a finalidade de exaltar às mesmas, não como princípio de igualdade, mas para estabelecer uma superioridade entre classes sociais.

Assim, observou-se que a materialidade dos discursos sobre a pessoa com deficiência física neuromotora/paralisia cerebral se encontra em um território que subverte esse sujeito, reforçando uma anormalidade produzida ideologicamente e que é atuante, objetivando moldá-lo para se constituir como normal, logo é indispensável que concepção socioantropológica seja exercitada com ações que permitem a perspectiva inclusiva.

\section{CONSIDERAÇÕES FINAIS}

Em síntese, perante as análises realizadas diante das produções artísticas (charges e filme), como também das publicações acadêmicas na área, se pode inferir que a maioria dos estudos apresenta um olhar clínico patológico. Isso porque, ainda observa-se o terapêutico em torno da pessoa com deficiência física neuromotora/paralisia cerebral, reduzindo sua existência a sua deficiência.

Nesse sentido, expressa-se que houve um anseio de romper com discursos ideológicos que associam essa deficiência como uma doença degenerativa ou em estado vegetativo; essas concepções materializam práticas de captura de um corpo doente para curá-lo, a partir de um padrão de normalidade.

A alteridade deficiente pode ser mais bem compreendida a partir da ruptura desses significados referidos à doença e ao déficit e suas ramificações na medicalização ${ }^{8}$ que não permanece restringida ao social, mas também ao pedagógico, pois se persiste na medicalização da deficiência no contexto escolar, limitando as oportunidades de aquisição e desenvolvimento de habilidades cognitivas, afetivas, linguísticas, psicomotoras, desde a infância.

Para isso, as concepções devem se respaldar na superação da visão binária e/ou organicista sobre a pessoa com deficiência física neuromotora/paralisia cerebral, objetivando

\footnotetext{
${ }^{8}$ Colocar os serviços da saúde dentro da educação, invés de propor a colaboração e/ou a parceria entre educação e saúde (BASIL, 2004). 
no avanço constante de ações que respeitem as diferenças, colaborando na formação de sua personalidade para se empoderar como interlocutora de discursos de resistências e lutas contra sua exclusão no contexto social.

\section{REFERÊNCIAS}

AMARAL, L. A. Sobre crocodilos e avestruzes: falando das diferenças físicas, preconceitos e sua superação. In: AQUINO, J. G. (Coord.). Diferenças e preconceito na escola: alternativas teóricas e práticas. São Paulo: Summus, 1998. p. 11-31.

BASIL, C. Os alunos com paralisia cerebral e outras alterações motoras. In: COLL, C.; MARCHESI, Á.; PALACIOS, J. (Orgs.). Desenvolvimento psicológico e educação. 2 . ed. Porto Alegre: Artmed, 2004. p. 215-233.

BEYER, H. O. Inclusão e avaliação na escola de alunos com necessidades educacionais especiais. 2. ed. Porto Alegre: Mediação, 2006.

BOBATH, B. Actividad postural refleja anormal causada por lesiones cerebrales. Buenos Aires: Panamericana, 1971.

BRASIL. Inclusão escolar de alunos com necessidades educacionais especiais: deficiência física. Brasília, DF: MEC/SEESP, 2006.

. Constituição da República Federativa do Brasil. Brasília, DF: Senado, 1988.

Lei $n^{\circ}$. 8.213, de 24 de julho de 1991. Dispõe sobre os Planos de Benefícios da Previdência Social e dá outras providências. Brasília, DF: Senado, 1991.

Saberes e práticas da inclusão: desenvolvendo competências para o atendimento às necessidades educacionais de alunos com deficiência física/neuro-motora. 2. ed. Brasília, DF: Mec/SEESP, 2006.

DISCHINGER, R. C. R.; MACHADO, R. Atendimento Educacional Especializado do aluno com deficiência física. 1. ed. São Paulo: Moderna, 2010.
GABY - uma história verdadeira. Direção: Luis Mandoki. Estados Unidos; TriStar Pictures, 1987, 1 filme (110 min.), sonoro, legendado, color.

GLAT, R. Orientação familiar como estratégia facilitadora do desenvolvimento e inclusão de pessoas com necessidades especiais. In: MENDES, E. G.; ALMEIDA, M. A. (Orgs.). A pesquisa sobre inclusão em suas múltiplas dimensões: teoria, política e formação. Marília, SP: ABPEE, 2012.

GIL, A. C. Como elaborar projetos de pesquisa. 4. ed. São Paulo: Atlas, 2008.

ISRAEL, V. L.; BERTOLDI, A. L. S. Deficiência físico-motora: interface entre educação especial e repertório funcional. Curitiba: Ibpex: 2010.

LEITE, J. M. R. S.; PRADO, G. F. Paralisia cerebral: aspectos fisioterapêuticos e clínicos. v. 12. no. 1. São Paulo: USP, 2004. https://doi. org/10.4181/RNC.2004.12.41

REBEL, M. F. et al. Prognóstico motor e perspectivas atuais na paralisia cerebral. Revista Brasileira Crescimento e Desenvolvimento Humano, São Paulo, v. 2, n. 20, p. 342-350, out./dez. 2010. https://doi.org/10. 7322/ihgd.19971

SILVA, L. G. S. Educação inclusiva: práticas pedagógicas para uma escola sem exclusões. 1. ed. São Paulo: Paulinas, 2014.

SKLIAR, C. Educação e exclusão: abordagens sócio-antropológicas em educação especial. Porto Alegre: Mediação, 1997.

A invenção e a exclusão da alteridade "deficiente" a partir dos significados da normalidade. Educação \& Realidade, v. 4, p. 17-32, n. 2, jun. 1999.

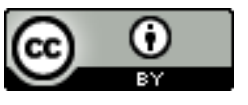

License information: This is an openaccess article distributed under the terms of the Creative Commons Attribution License, which permits unrestricted use, distribution, and reproduction in any medium, provided the original work is properly cited. 
Artigo recebido em 14 de maio de 2018.

Avaliado em 05 de setembro de 2018.

Aceito em 09 de setembro de 2019.

Publicado em 02 de outubro de 2019.

\section{Como citar este artigo (ABNT):}

ALMEIDA JÚNIOR, Claudovil Barroso de. A materialidade dos discursos sobre a pessoa com deficiência física neuromotora/paralisia cerebral. Estação Científica (UNIFAP), Macapá, v. 9, n. 1, p. 09-19, jan./mar. 2019. 